machinery from the international centres at Geneva or elsewhere to the national components. He quoted his chief, Dr. Brock Chisholm, as stating that perhaps the success of W.H.O. should be judged not by the amount of money which it could persuade its member Governments to spend in the international field, but by the amount which it could persuade them to spend on health in their own countries.

In his presidential address to the World Federation, Professor LINE made the point that the man in the street had confidence in the leadership of medicine so far as his physical needs were concerned, and was content that medicine should advise public-health departments in the interests of his own physical and environmental well-being. He had in fact handed over his responsibility in this respect to professional medicine, and medicine was worthy of the trust. But the man in the street must be made to realize that in the field of mental health, involving the effectiveness with which he could live with other people and with himself, he could not afford to delegate his responsibility. This was something that could not be turned over to the expert because it concerned personality development, character formation, and social adaptation, which last was expressed in that loosely used word "democracy."

\section{The Language of Science and of Industry}

The discussion on mental health in industry was opened by Dr. R. F. TRedgold, who made the point that it was not so much more knowledge on this subject which was required, as the better application of the knowledge already existing. He also said that the results of scientific research were quite frequently made public in a manner as remote as possible from the understanding of the industrialist, who was expected to approve them and incorporate them in his organization. The language of science was as far apart from that of industry as English was from French-indeed, it was farther apart, because when the industrialist came upon scientific language (which he was apt to call "jargon") his inhibitions were at once aroused, and he tried not to understand it, whereas the Englishman, faced with a presentation in French, regarded it as a challenge and did his best to understand it. The psychiatrist, said Dr. Tredgold, should be aware of the suspicion and uncertainty with which the industrialist regarded him. A frank statement of his aims, qualifications, and practices was at least the first step towards a better understanding.

He reminded the assembly of three cross-currents which were now operating: (1) while all were agreed that prevention was better than cure, preventive work was less attractive to the student and to the practitioner; (2) the advance of psychiatric treatment during the last 20 years, and perhaps the next 10 , might gradually result in a diminution of the "chronic" population of mental hospitals, and thus release many psychiatrists for fields of work outside the hospitals; (3) in spite of what he had already said about the latent antagonism of the industrialist, it already seemed to be accepted by industrialists, who had the reputation of being hard-headed business people, that in financial terms the value of such mental-health services as had been planned and put into operation in industry had been worthy of their support.

\section{Displaced Persons}

The subject of the mental health of homeless and "transplanted" persons was developed by Professor JOHN COHEN, professor of psychology in the Hebrew University, Jerusalem. Human transplantation, he said, was as old as Adam. In fact, Adam was the first transplanted person, and perhaps his transplantation to a less comfortable environment might account for the delinquency of one of his offspring, who slew his brother. Moreover, displaced persons were not only groups vaguely thought of as moving about rather aimlessly in distant parts of the world, but were in our own community-the child taken from home to hospital, the old person removed from domestic independence to a home for the aged, the conscript entering the Army. What was new in the situation, he said, was not the phenomenon itself but the deliberate attempt or intention to reduce its hardship and to dovetail the life of the newcomer into that of the receiving community. The integra- tion was always going on, and there were indices by which its process could be measured-the comparative literacy of the immigrants and the native groups, the extent of inter-marriage, the vital and morbid statistics of each, and the comparative industrial productivity.

One aspect of the problem of integration was the elimination of tensions. Tension, said Professor Cohen, was a central concept in psychology. It was a pity that it had been rather isolated from other concepts such as frustration and conflict; for all three cohered in the same framework. Each type of frustration or conflict produced a different kind of tension, and an analysis of these different forms of tension, above all in the social sphere, should be attempted.

One of the reports presented to the meeting concerned the results of an inquiry into training facilities in psychiatry and allied mental-health disciplines. Replies so far have been received from no more than a dozen countries, not including Great Britain. The replying country in which there is the most abundant provision is the United States. At the present time the approximate annual output of trained psychiatrists from training institutions in the U.S.A. is 500 . It is estimated that approximately that number of medical graduates complete each year a comprehensive systematic training course in psychiatry covering a period of three years. There are 253 hospitals, institutions, and other training centres in the U.S.A. which are recognized by the medical profession as providing acceptable training. Three-year advanced training courses are provided by 10 approved psycho-analytic institutes, and an average of 21 psycho-analysts complete this training annually.

\section{Nova et Vetera}

\section{GIORDANO BRUNO AND THE CIRCULAR MOTION OF THE BLOOD}

So far, Giordano Bruno (1548-1600), the philosopher of pantheism and martyr of science, does not seem to have been cited in connexion with the discovery of blood circulation. I have no intention of claiming a share in this discovery for Bruno. I wish, however, to put on record several passages in which Bruno emphasizes the "circular" pattern of the motion of the blood. He says: "The spiritual life-force is effused from the heart into the whole of the body and (flows back) from the latter to the heart, as it were from the centre to the periphery and from the periphery to the centre, following the pattern of a circle. ... The material part of all these spirits is a fluid which cannot move on its own account, but by means of its innate spirit. Hence there is no circular or sphaerical motion outside the body, for the blood, which in the animal moves in a circle in order to distribute its motor, the spirit, lies immovable outside the body, is inert and decays, no longer deserving the name of blood" (De Rerum Principiis. 1590. A certainly genuine though posthumous treatise from the “ Noroff Collection," edited by F. Tocco and H. Vitelli. Opp. Latina. Florence, 1891, p. 521.).

He also says that "in us the blood and other fluids are being moved continually and very rapidly in a circle, flow and flow back, are diffused from the centre into the extreme periphery and from there return to the centre-a movement for which the followers of Aristotle give far-fetched and confused reasons such as an instinct of nature, the necessity of fate, the providence of God, etc." (The italics are mine.)

There are also allusions to the circular motion of the blood in two of his better-known treatises (De Immenso, VI, 8; De Monade, 1591, p. 23). The ideological background to this is (a) his most probable acquaintance with Caesalpino, the wellknown Aristotelian philosopher, naturalist, and precursor of Harvey, the first to use the term "circulatio" (1571), and (b) Bruno's belief in the perfection of the circle as the fundamental symbol of all life and action in the cosmos (De Triplici Minimo, I, 3 ; De Monade, I, 2). The above passages from Bruno show that Caesalpino's idea of "circulatio" was alive in a general philosophical form towards the end of the sixteenth century.

Walter Pagel. 